produced by a fused Julesz pair, be stored eidetically, or only a monocular pattern ? It will be difficult to interpret further observations unless the answers to those questions are known with some confidence.

This is such a fascinating field of study that there must be a strong temptation to run through many casual exporiments on a great variety of visual phenomena. The literature, however, contains many tantalizingly incomplete reports of exceptional cases that can be all too readily dismissed by the sceptic. We should like to urge that this unique research opportunity be used to obtain data of such quality and ineontrovertible detail to ensure a permanent impact on the study of vision. And we should like to stress the urgency of this need while the subject is still readily available and before the results slip into the archives as one more perplexing, unconfirmable enigma.

Physiological Laboratory, University of Cambridge.

Psychological Laboratory,

University of Cambridge.

COLIN BLAKEMORT

Brain and Perception Laboratory,

Department of Anatomy,

University of Bristol.

Received February 23, 1970

' Stromeyer TIT, C. F., ant Psotka, J., Natzue, 225, $346(1970)$.

'Julesz, B., Bell System Tech. J., 39, 1125 (1960).

${ }^{3}$ Barlow, H. B., Blakemors, C., and Yettigrew, J. D., J. Physiol., 193, 327 (1967).

${ }^{4}$ Nikara, T., Bishop, P. O., and Pettigrew, J. D., Exp. Brain Res., 6, 353

${ }^{5}$ Hubal, D. H., and Wicssl, T. N., Nature, 225, $41(1970)$.

${ }^{8}$ Sanderson, K. J., Darian-Smith, 1., and Bishop, P. O., Vision Res., 9, 1297 (1969).

${ }^{7}$ Julesz, B., Science, 145, 356 (1964).

\section{Mandible of Archaeopteryx provides an Example of Mosaic Evolution}

THe upper Jurassic fossils Archaeopteryx lithographica and $A$. siemensii Dames offor the only direct evideneo of the morphological transition between reptiles and birds. There is therefore a large literature about these fossils, which deBeer ${ }^{1}$ has summarized. Much attention has centred on the structure of the skull and its similarities and differences with those of reptiles and birds ${ }^{1-5}$. Unfortunately, the structure of the lower jaw has been entirely neglected, or casually dismissed, as reptilian rather than avian, principally because of the presence of thecodont teeth. I have been able to study the morphological dis. tinctions between the lower jaws of reptiles and birds, and tho results have a direct bearing on the level of organization (morphological grade) of Archaeopteryx.

Heilmann ${ }^{3}$ and Gregory ${ }^{6}$ pointed out that the visibility of the splenial on the lower edge of the jaw (seen in lateral view) in Archaeopteryx (Fig. $1 A$ ) is definitely a reptilian feature, but neither of them offered comments on the arrangement of the other bony elements. In reptiles with a mandibular fossa, however (Fig. I $B$ ), the ventral border of the fossa (in lateral viow) is compused entirely or predominantly of the angular bone ${ }^{7,8}$. The dentary either does not form the border or does so only to a minor extent. In modern birds (Fig. IC), on the other hand, the ventral border of the fossa is formed exclusively (or nearly so) by the dentary, the angular being excluded posteriorly or medially. Heilmann ${ }^{3}$, after stating that "the lower jaw is among the most markedly defined parts of the skull", reconstructed the mandible of Archaeopteryx as in Fig. 1A. It can be seen
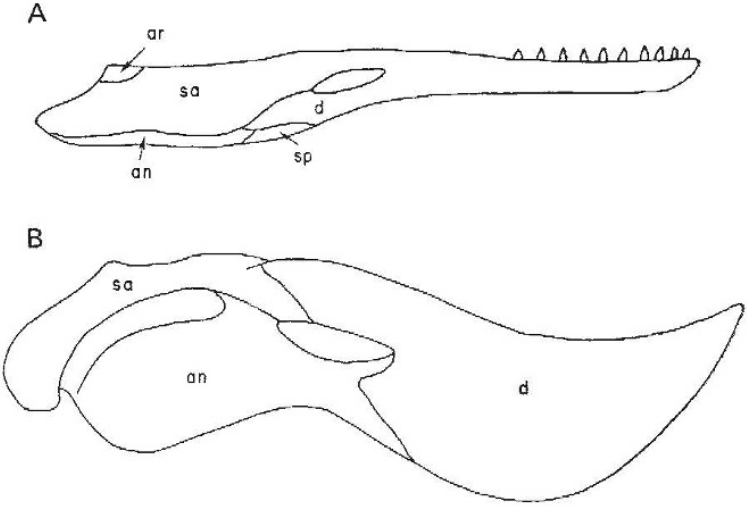

C

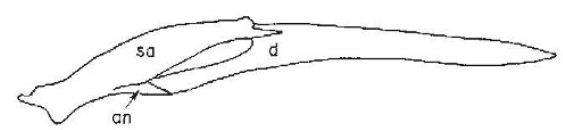

Fig. 1. Lower jaws of (A) Archaeopteryx siemensii (after Heilmann), (B) Dicynodon sp. (after Romer), and (C) Sternu albifrons. an, Angular ar, articular; $d$, dentary; sa, surangular; sp, splenial. Drawings are

that the dentary comprises tho entire ventral border of the fossa, thus conforming to the pattern of modern birds and not reptiles. The differences $I$ have described are true for all reptiles and birds I have examined and undoubtedly represent valid generalizations. Unfortunately, many reptiles do not possess a mandibular fossa, and in these cases I have been unable to discorn a pattern of tho bony elements which differentiates them from birds Most birds lack a well developed mandibular fossa, but almost all orders, and many families, have representatives with either a fossa or a narrow slit between the bony elements; this slit is presumably the remmant of the fossa. In both of these conditions the avian pattern of the elements was found to exist. The mandibular fossa of Archaeopteryx is located quite far anteriorly for either a bird or reptile, and so casts some doubt on the accuracy of Heilmann's reconstruction. This problem will probably remain unresolved until additional specimens are discovered.

The evidence I have presented suggests that the lower jaw of Archaeopteryx, like other morphological structures in "transitional" forms, is composed of both primitive and advanced characters and is therefore a good oxample of mosaic evolution'. The mandible of Archaeopteryx is not strictly reptilian in its structure, and thus indicates that the skull as a whole may be more advanced toward the avian lovel of organization than previously suggested.

I thank Drs Walter J. Bock, Edwin W. Colbert, Kenneth C. Parkes, and Alexander Wetmore for reading and discussing this communication. I also thank the Frank M. Chapman Memorial Fund of the American Museum of Natural History for financial support.

Joel Cracraft

Department of Ornithology,

American Musoum of Natural History,

New York City, New York 10024.

Received February 24, 1970.

1 DaBeer, G., Archaropteryx lithozraphica (British Musaum (Natural History), London, 1954).

2 Dames, W., Palacontol. Abhandl, 2,117 (1884).

${ }^{3}$ ITeilmann, G., The Origin of Birls (Appleton, New York, 1927).

${ }^{4}$ Lowe, P., Ibis, 86, 517 (1944).

s Simpson, G. G., Bull. Amer, Mus, Nat. Hist., 87, (Art 1), 1 (1916).

6 Gregory J. T., Condor, 54, 73 (1952)

${ }^{7}$ Romer, A. S., Osteology of the Reptiles (University of Chicago Press, 1956).

${ }^{8}$ Romer, A. S., Verlebrate Palaiontology (University of Chicago Press, 1986).

- DeBeer, G., Adv. Sci.,11, 160 (1954). 